\title{
Relations Among Psychotherapists' Epistemic Orientation, Personal Style and Emotion Regulation
}

\author{
Emanuel Missias Silva Palma* (D) \& Sônia Maria Guedes Gondim (D) \\ Universidade Federal da Bahia, Salvador, BA, Brasil
}

\begin{abstract}
The main objective of this study was to examine the relations among psychotherapists' epistemic orientation (i.e., intuitive, empiricist, and rationalist), personal style and emotion regulation strategies. Participants in the study were 674 psychotherapists of different theoretical approaches, who completed an online questionnaire containing measures of epistemic orientation, personal style, and emotion regulation strategies. Psychotherapists profiled as predominantly intuitive tended towards broader attention and greater emotional closeness as compared to those profiled as predominantly rationalist or empiricist. Furthermore, they also reported using more strategies for increasing the effects of positive emotions than rationalists. Implications for training, practice and therapist well-being are discussed.
\end{abstract}

KEYWORDS: epistemic orientation, personal style, emotion regulation, psychotherapist

\section{Relações entre a Orientação Epistêmica, o Estilo Pessoal e a Regulação Emocional de Psicoterapeutas}

\begin{abstract}
RESUMO - O objetivo principal deste estudo foi examinar as relações entre orientação epistêmica (i.e., intuitiva, empiricista e racionalista), o estilo pessoal e as estratégias de regulação emocional de psicoterapeutas. Participaram do estudo 674 psicoterapeutas de diferentes abordagens teóricas, os quais responderam a um questionário online contendo medidas de orientação epistêmica, estilo pessoal e estratégias de regulação emocional. Os terapeutas predominantemente intuitivos apresentaram uma maior tendência à abertura da atenção e à proximidade emocional quando comparados aos terapeutas predominantemente empiricistas ou racionalistas. Além disso, relataram usar mais estratégias para o aumento dos efeitos das emoções positivas do que os racionalistas. Discutem-se implicações para a formação, prática e bem-estar pessoal do psicoterapeuta.
\end{abstract}

PALAVRAS chave: orientação epistêmica, estilo pessoal, regulação emocional, psicoterapeuta

Research on therapists' personal attributes has significantly improved our understanding of the effectiveness of psychotherapy (Baldwin \& Imel, 2013; Nissen-Lie et al., 2015). Indeed, the research literature has increasingly shown that certain therapist characteristics greatly contribute to the development and maintenance one of the most robust predictors of clinical efficacy: the therapeutic alliance, generally understood as the quality and strength of the collaborative bond between therapists and their clients (Fife, Whiting, Bradford, \& Davis, 2014; Heinonen et al., 2014).

However, little is known about how therapist characteristics develop and what their most significant correlates and predictors are. Some scholars argue that this occurs because excessive emphasis is placed on how therapists' individual characteristics impact treatment outcomes. Such attention might highlight the field's pragmatic concerns over issues relating to therapists' own ways of behaving, professional background, and personal development (Fife et al., 2014; Lee, Neimeyer, \& Rice, 2013; Rønnestad \& Skovholt, 2013). In this sense, Knight (2012) and Rønnestad and Skovholt (2013) hold that the investigation of therapists' personal characteristics can promote self-reflection, self-control, and personal well-being. Furthermore, research into this area might

*Email: emanuelmssilva@gmail.com

- Submetido: 26/05/2016; Revisado: 14/06/2017; Aceito: 08/05/2018. 
generate invaluable resources for training and personal and professional development.

In this regard, Orlinsky and Rønnestad (2005) argue that empirical and systematic research on therapists' essential characteristics can foster collective self-knowledge and supplement a literature which has traditionally relied on eminent psychotherapists' personal observations. In this context, the present study focuses on the relations among therapists' epistemic orientation, personal style, and emotion regulation strategies.

\section{THERAPIST'S PERSONAL STYLE: DIMENSIONS, CHARACTERISTICS AND ASSOCIATIONS}

Therapist's personal style has been the subject of different theoretical and empirical studies that seek to understand the impacts of its different dimensions on varied aspects related to clinical practice (Fernández-Álvarez, García, Lo Bianco \& Santoña, 2003; Heinonen et al., 2014). In this study, we adopted Fernández-Álvarez et al. 's (2003) perspective, according to which personal style is a critical component of the therapeutic process. It refers to the distinctive manner in which therapists play their professional role. It is a multidimensional construct consisting of functions that express the attitudes, risks, and dispositions therapists demonstrate in their clinical practice.

This style may arise from the interaction among different variables, such as professional background, dispositional traits, and dominant communication modes (Fernández-Álvarez et al., 2003). In this context, these authors proposed a conceptual model of therapist's style consisting of five basic functions, namely attention, involvement, expression, instruction, and operation. In accordance with this model, therapist's style can be identified through the interaction among these five basic functions, which can be assessed along a bipolar continuum: (a) attention (ranging from broadly focused to narrowly focused), which refers to the selection of clinically relevant information; (b) involvement (ranging from low to high degree), which reflects therapists' level of involvement with their work; (c) expression (ranging from distant to close), which refers to the affective communication with clients; (d) instruction (ranging from rigid to flexible), which refers to the procedures used to regulate the therapeutic setting (e.g., schedule and fees), and (e) operation (ranging from unplanned to structured), which reveals how clinical interventions are implemented.

Empirical studies have identified several associations between the different dimensions of therapist's style and professional variables. Psychoanalytically- and humanisticoriented therapists, for instance, have tended to lean more toward broadly focused attention and unplanned operation whereas cognitive therapists have preferred to narrowly focus their attention and to operate in a more structured manner (Carvalho, Corbella, \& Matos, 2011; Castañeiras et al., 2008; Palma \& Gondim, 2016). Regarding the duration of treatment, therapists providing brief interventions have shown more narrowly focused attention and structured operative style (Castañeiras et al., 2008). As a rule, these findings have empirically demonstrated that therapists' professional variables are predictive of their stylistic patterns. However, the impact of therapists' epistemic orientation on their personal style and emotion regulation has yet to be clearly determined.

\section{THERAPIST'S EMOTIONAL EXPERIENCES AND THEIR REGULATION}

Therapists' emotional experiences have recently sparked interest among researchers. Concerns over therapist's affective dimension rests on the premise that emotions play a critical role in clinical practice and in therapist's personal well-being (Hofman, 2016; Vandenberghe \& Silvestre, 2014). In this vein, different approaches to psychotherapy acknowledge that emotions can inform clinical practice. Indeed, diverse emotion regulation strategies are recommended to manage therapists' own emotional responses with the aims of producing positive therapeutic outcomes (Hofman, 2016; Vandenberghe \& Silvestre, 2014).

As is the case with the research agenda on therapist's personal style, the emphasis is typically placed on how therapist emotional reactions might influence treatment outcomes (Burt, 2013). Thus, the field of therapists' individual emotion regulation still lacks systematic research, particularly in the present context in which therapists' training, development, and well-being have been increasingly valued (Hofman, 2016).

Emotion regulation refers to the processes through which individuals modify different aspects of their emotional experience (e.g., its intensity, meaning, and context of ocurrence) in order to achieve a goal (Gross, 2015; Tamir, 2015). Its clinical significance is widely known and has been revealed though a series of studies showing moderate to strong associations with indices of well-being, mental health, cognitive functioning, and interpersonal relationships (Gross, 2015; Nelis, Quoidbach, Hansenne, \& Mikolajaczak, 2011). 
A growing body of literature recognizes that most individual efforts to regulate emotions are oriented towards the maintenance or the increase of the beneficial effects of positive emotions by using upregulation strategies (e.g., savoring the present moment and capitalization of positive emotions) or towards the buffering of the harmful effects of negative emotions by using downregulation strategies (e.g., cognitive reappraisal and emotional expression) (Nelis et. al., 2011; Tamir, 2015).

This model of emotional management is based on two regulatory processes (i.e., upregulation and downregulation) and has been predictive of different dimensions of psychological functioning. In psychotherapy, for instance, patients' deficits in emotion regulation have been associated with several psychological disorders and have been the focus of considerable research (Gross, 2015; Nelis et al., 2011). So far, however, far too little attention has been paid to therapists' emotion regulation. Furthermore, when it is approached, it tends to refer to therapists' management of negative emotions inside and outside the sessions (Burt, 2013; Pletzer, Sanchez, \& Scheibe, 2015).
Tamir (2015) argued that studies on emotion regulation have primarily focused on the content and the process of the regulation strategies instead of focusing on the motivational determinants of emotional management. In this vein, she proposes a taxonomy of motives in emotion regulation to guide future research. Among others, this taxonomy encompasses epistemic motives, which refer to the acquisition and knowledge about oneself and the world. Such epistemic motives, as suggested by Tamir, might guide individuals' emotion regulation strategies, thus promoting either positive or negative emotions and confirming information regarding themselves and their surrounding environment. For instance, in a comparative study by Millgram, Joorman, Huppert, and Tamir (2015), depressed individuals were more likely to choose strategies that intensified their sadness and apathy when compared to nondepressed individuals. To some extent, these findings seem to suggest that the use of emotion regulation strategies is associated with individual orientation to knowledge, especially self-knowledge.

\section{EPISTEMIC ORIENTATION: DEFINITION, DIMENSIONS AND POSSIBLE ASSOCIATIONS WITHTHERAPIST CHARACTERISTICS}

Epistemic orientation may refer to an individual's preferred way of accessing and using knowledge (Lee et al., 2013; Rancourt, 1990) or to the philosophical assumptions regarding the construction of reality and the testing of personal beliefs about knowing (Royce \& Mos, 1980). Royce and Mos's (1980) model suggests that individuals have an epistemic style or orientation resulting from the interaction among three basic ways, or modes, of knowing, namely rationalism, empiricism, and metaphorism. Rationalism focuses on logical consistency and analytic, conceptual thinking. Empiricism involves perceptual, sensory experiences and observations. Metaphorism, in turn, concentrates on symbolic experience and affective, intuitive aspects. The metaphorical mode was later termed noetic (i.e., intuitive) by Rancourt (1990) in an attempt to accentuate its intuitive components.

These ways of knowing interact among themselves, and their hierarchical arrangement helps identify an individual's epistemic style or orientation. For example, an individual may have a rational-empiricist-metaphorical (REM) orientation, with rationalism as his/her dominant mode (i.e., more frequently used) whereas empiricism and metaphorism are the associated and minor modes, respectively. As such, Royce and Mos's (1980) model allows the identification of six stylistic arrangements resulting from the combination of the basic modes of knowing (e.g., ERM and MRE). It is important to underscore that, in this model, the dominant mode represents individuals' most characteristic or usual way of understanding knowledge, that is, their predominant epistemic orientation.

In psychotherapy research, epistemic orientation has been associated with therapists' theoretical preferences, use of techniques, and coping strategies. In a study on personality traits, epistemic orientation, and theoretical orientation choice by British therapists, Arthur (2000) found that psychoanalytically-oriented therapists were more likely to describe themselves as metaphorical, thus relying more often on feelings and intuitions as sources of information whereas cognitive-behavioral therapists tended to emphasize logical and rational processes. In terms of clinical practice, Lee et al. (2013) found evidence that therapists leaning towards rationalism were more likely to select directive strategies to change irrational thoughts (e.g., counseling and cognitive restructuring) as opposed to their construtivist counterparts, who preferred a greater variety of strategies (e.g., directive and emotional processing interventions). Furthermore, epistemic orientation seems to influence therapists' self-care strategies. In a study by Brucato and Neimeyer (2009), for instance, constructivist epistemic commitment predicted psychotherapists' use of self-care and coping strategies. Taken together, these findings seem to indicate that epistemic orientation might influence different dimensions of therapists' behavior, such as their stylistic patterns and emotion regulation strategies. 
In this context, the objective of the present study was to examine the associations among therapists' epistemic orientation (intuitive, rationalist or empiricist), different dimensions of therapist's personal style (attention, operation, expression, and involvement) and emotion regulation modes (upregulation of positive emotions and downregulation of negative emotions). Additionally, therapists' predominant epistemic orientations were identified in the sample of the present study. As such, when the terms empiricist, intuitive, and rationalist are used in this article, they refer to therapist's predominant epistemic orientation as conceptualized by Royce and Mos (1980).

Even though theoretical claims have been made regarding the associations between therapists' personal epistemologies and personal characteristics, little empirical research has tested such relationships (Downing, 2000; Lee et al.,
2013; Toska et al., 2010). In this context, Downing (2000) holds that the study of therapists personal epistemologies must surpass the simple description of epistemic traits or atributes and should be oriented towards understanding the lived modes of knowing, that is, how therapists' personal epistemologies are manifested in their practice. Furthermore, Rønnestad and Skovholt (2013) suggest that studies similar to the one presented here might contribute to the discussion of issues associated with therapists' training and personal development by raising therapists' awareness of the determinants of their behaviors and feelings. This may, in turn, help therapists become more skilled at managing the intra- and interpersonal aspects affecting their professional practice and personal well-being (Fife et al., 2014; Levitt \& Piazza-Bonin, 2015; Pieterse, Lee, Ritmeester, \& Collins, 2013).

\section{METHOD}

\section{Participants}

Participants in the study were 674 psychotherapists, aged 22-78 $(M=42,02, S D=13,06)$. Most were women, $78,5 \%(n=529)$. In terms of academic background, $88,6 \%$ $(n=597)$ self-identified as psychologists, 7,3\% $(n=49)$ as medical doctors and $4,2 \%(n=28)$ as other (e.g., social workers, nurses, and pedagogues). Participants indicated the following as their predominant theoretical orientations: psychoanalytic, $25.2 \%(n=170)$; behavior-analytic, $19.6 \%(n=132)$, cognitive, $18.2 \%(n=123)$, humanisticexistential, $13.4 \%(n=90)$, analytical, $11.4 \%(n=77)$, systemic, $7.4 \%(n=50)$ and other, $4.8 \%(n=32)$. Other involved approaches such as psychodrama, esquizo-analysis, and integrative.

In terms of their primary work setting, most, $92 \%(n=$ 620 ) worked in private practice (i.e., in the office) whereas $4.5 \%(n=30)$ and $3.3 \%(n=20)$ worked in hospitals and Psychossocial Attention Centers (CAPs), respectively. Years of experience ranged from 1 to $50(M=12.84, S D=11.18)$. Twenty one psychotherapists had been working for less than one year at the time of data collection. Furthermore, participants reported working an average of 23.49 hours per week $(S D=13.9$, range 1 to 40$)$.

\section{Instruments}

Cuestionario del Estilo Personal del Terapeuta (Therapist's personal style Questionnaire/EPT-C short version). It is a six-point Likert-type questionnaire consisting of 18 items. Participants indicate the extent to which the items describe them $(1=$ does not describe me at all, 6 = describes me very well). It was developed by Castañeiras et al. (2008) and validated in the Brazilian context by Palma and Gondim (2016). The measure had good fit indices after removing the instruction dimension. The version of the scale used in the study consists of the following dimensions: attention (four items; e.g., I like to feel surprised by what each patient brings to the session without having preconceived notions.); involvement (four items; e.g., I think about patients' problems even after sessions.), expression (five items, e.g., Real changes take place during highly emotional sessions.) and operation (five items; e.g., I prefer treatments where everything is programmed.). In the present study, the internal consistency of the dimensions was calculated using average variance extracted (AVE): attention (0.64), involvement (0.64), expression (0.63), and operation (0.72). Average scores are calculated for each dimension, with the higher scores indicating greater levels of the assessed function, for instance: attention (more narrowly focused), involvement (greater degree), expression (greater closeness) and operation (more structured). The instruction dimension was excluded from the present study for showing very low internal consistency (0.45).

Epistemic Orientation Short Scale. It is a six-point Likert-type scale consisting of 11 items. Participants indicate the extent to which the items describe them $(1=$ does not describe me at all, 6 = describes me very well). Its purpose is to identify an individual epistemic orientation based on the hierarchical arrangement of the three modes of knowing 
proposed by Royce and Mos (1980) and Rancourt (1990). It consists of three dimensions, namely: intuitionism, which involves knowledge acquisition and use based on affective and intuitive experiences (four items, e.g., I deal best with contexts involving mainly spontaneity and sensitivity.); rationalism, which involves knowledge acquisition and use through rational thinking (four items, e.g., I tend to make decisions based on reasons I can clearly explain.), and empiricism, which involves knowledge acquisition and use through observations and concrete experiences (three items, e.g., In new situations, I acquire knowledge based on observation and practical experiences.). It was developed and validated in the context of the present research project and exhibited good fit to the data (Palma, Gondim, \& Aguiar, 2018). The internal consistency of the dimensions was calculated using the average extracted variance (AVE): Intuitionism (0.82), Rationalism (0.79), and Empiricism (0.79). Average scores were calculated for each factor, with the highest scoring factor of the three indicating the individual's predominant epistemic orientation mode.

Emotion Regulation Profile - Revised (ERP-R Short Version). It is a six-point Likert-type measure used to assess individual differences in emotion regulation. Participants indicate the probability of using different emotion regulation strategies $(1=$ very unlikely to use, $6=$ very likely to use $)$ in six emotion-eliciting vignettes (three for positive emotions and three for negative emotions) in different domains, such as work, leisure, and interpersonal relationships (e.g., carrying out an important task, a romantic trip with a partner during the weekend). Each vignette encompasses a predominant emotional reaction and is followed by four options of regulation strategies that could be used in that situation. These strategies are divided into upregulation strategies that aim at maintaining or increasing the effects of positive emotions (e.g., savoring the present moment and sharing positive emotions) and downregulation strategies that aim at buffering the harmful effects of negative emotions (e.g., expression of negative emotions and cognitive reappraisal). The original measure was developed by Nelis et al. (2011) and was adapted into the shortened version used in the present study by Gondim et al. (2015). As simplified examples of ERP-R vignettes, we have the following situations: (1) It is the last day of your trip, and you find a waterfall, a beautiful landscape, that elicits a feeling of admiration. In this situation, you choose to connect with the present moment with all your senses (adaptive strategy).

(2) In another context involving the oral presentation of a subject, a situation that might elicit strong feelings of anxiety, you may choose to reappraise that situation by thinking that you have done this before, so, in case anything goes wrong, it will not be a catastrophe (functional strategy). The original instrument's reliability was considered good $(a=0.89)$. In the present study, Cronbach alphas for each dimension were $a=0.70$ for upregulation strategies and $a$ $=0.65$ for downregulation strategies.

A questionnaire containing professional and demographic information. It is a form containing questions related to topics such as age, sex, years of experience, primary working setting, and predominant theoretical orientation.

\section{Data Collection}

An online link containing the invitation to participate in the study was sent to psychotherapists who were members of national societies or associations (e.g., Brazilian Federation of Psychoanalysis, Brazilian Association of Behavior Medicine and Psychotherapy). Psychotherapists were also contacted via their professional websites and advertising sites. After reading the consent form and agreeing to participate in the study, participants completed the online version of questionnaire. The link containing the questionnaire was visited by 1.233 individuals, and the questionnaire was completed by 674 (54.9\%) psychotherapists. The larger project of which this study is a part was approved by the Institutional Review Board at Faculdade Adventista da Bahia (CAAE: 37816214.7.0000.0042)

\section{Data Analysis}

The following assumptions were tested via visual inspection (e.g., histograms and scatterplots) and statistical procedures: a) linearity, b) homogeneity of regression gradients with nonsignificant interaction term $(p>0.05)$, c) normality via standardized residual analysis (Shapiro-Wilk's test $p>0.05$ ), and d) homoscedasticity and homogeneity of variances (via scatterplots and Levene's test, $p>0.05$ ). Furthermore, standardized residuals analysis $( \pm 3)$ revealed no extreme values.

Predominant epistemic orientations were assessed using measures of central tendency. To examine the associations among epistemic orientation modes, personal style dimensions and emotion regulation modes, Pearson correlation was used. Between-group differences in personal style dimensions and emotion regulation modes as a function of predominant epistemic orientation was tested using multivariate analysis of covariance (MANCOVA) with years of experience, age, and theoretical orientation as covariates. 


\section{RESULTS}

Therapists' Epistemic Orientation According to Age, Sex, and Years of Experience

Based on their highest scores on the dimensions of the Epistemic Orientation Short Scale, therapists were divided into three groups: predominantly intuitive, or intuitives ( $n$ $=143$ ), predominantly empiricist, or empiricists $(n=320)$, and predominatly rationalist, or rationalists $(n=94)$. Out of the 674 therapists in the study sample, 117 could not have their predominant epistemic orientation identified since they scored the same on two or on the three dimensions of the scale. Thus, such cases were excluded from the MANCOVA.

One-way ANOVAs were used to examine differences in therapists' predominant epistemic orientations according to age and years of experience and a chi-square analysis was used to test differences in sex distribution. Significant differences were found for sex, $F(2,553)=10.02, p<$ 0.01 , and years of experience, $F(2,553)=12,78, p<$ 0.001 . Predominantly rationalist therapists were younger $(M=36.94, S D=11.81)$ than empiricists $(M=41.56, S D=$ 13.07) and intuitives $(M=44.55, S D=12.80)$. Furthermore, rationalists were less professionally experienced $(M=7.26$, $S D=8.66)$ than empiricists $(M=12,60, S D=11,19)$ and intuitives $(M=14,40, S D=11,56)$. All ps were $<0.001$.

\section{Epistemic Orientation, Personal Style and Emotion Regulation Modes: Characterizing Associations and Group Differences}

Table 1 shows the correlations among epistemic orientation modes, personal style dimensions, and emotion regulation modes. As can be seen, low to moderate correlations were found among study variables. There were moderate negative correlations between intuitionism and the attention and the operation dimensions of therapist's style. Intuitionism was also moderately positively correlated with expression and upregulation. Rationalism, in turn, was moderately negatively associated with operation and weakly positively correlated with downregulation. It was also weakly correlated with expression. Empiricism was weakly positively correlated with expression and up- and downregulation. In terms of correlations between emotion regulation modes and personal style dimensions, downregulation was weakly negatively correlated with attention and involvement. Upregulation was weakly positively correlated with expression and negatively with attention.

MANCOVA was followed by univariate tests and showed statistically significant between-groups differences in attention, $F(2,546)=6.28, p<0.001$ and expression, $F(2$, $546)=7.36, p<0.001$. No statistically significant differences were found in involvement, $F(2,546)=0.32, p=0.72$ and operation $F(2,546)=2.59, p=0.07$. Post hoc analysis (with Bonferroni adjustment) were carried out to identify group differences. Table 2 presents the adjusted mean scores and standard errors for each therapist's style dimension as a function of therapists' predominant epistemic orientation.

In general, compared to empiricists or rationalists, intuitives scored lower in attention and higher in expression. Empiricists scored higher than intuitives and lower than rationalists in attention. However, no statistically significant differences were found between rationalists and empiricists in expression.

Table 1

Means, Standard Deviations and Correlations among Study Variables

\begin{tabular}{|c|c|c|c|c|c|c|c|c|c|c|c|}
\hline & $\mathbf{M}$ & SD & 1 & 2 & 3 & 4 & 5 & 6 & 7 & 8 & 9 \\
\hline 1. Empiricism & 4.92 & .83 & - & & & & & & & & \\
\hline 2. Intuitionism & 4.25 & 1.09 & $.25^{* *}$ & - & & & & & & & \\
\hline 3. Rationalism & 4.09 & 1.04 & $.34 * *$ & $-.17 * *$ & - & & & & & & \\
\hline 4. Attention & 3.08 & .99 & $-.08 *$ & $-.45^{* *}$ & $.19^{* *}$ & - & & & & & \\
\hline 5. Involvement & 3.31 & .95 & .01 & .04 & .01 & .04 & - & & & & \\
\hline 6. Expression & 3.80 & .98 & $.12^{* *}$ & $.43 * *$ & $-.12 * *$ & $-.46 * *$ & $.08 *$ & - & & & \\
\hline 7. Operation & 2.27 & .94 & .05 & $-.27 * *$ & $.30 * *$ & $.44 * *$ & -.01 & $-.14 * *$ & - & & \\
\hline 8. Upregulation & 4.85 & .82 & $.24 * *$ & $.31 * *$ & .03 & $-.10 *$ & .02 & $.13 * *$ & -.03 & - & \\
\hline 9. Downregulation & 4.72 & .95 & $.11 * *$ & .02 & $.15^{* *}$ & -.01 & $-.14 * *$ & $-.13 * *$ & .05 & $.12^{* *}$ & - \\
\hline
\end{tabular}

Note. For persoanl style dimensions, high scores to the right of the continuum of each dimension represent: attention (more narrowly focused), involvement (greater degree), expression (greater closeness) and operation (more structured). For this analysis, all 674 cases were considered. Likert-type scales had six points, ranging from 1 to 6 .

$* \mathrm{p}<0,05 . * \mathrm{p}<0,001$ 
Adjusted Mean Scores in the Four Dimensions of Therapist's personal style as a Function of Predominant Epistemic Orientation

\begin{tabular}{lccccccc}
\hline & \multicolumn{7}{c}{ Predominant Epistemic Orientation } \\
\cline { 2 - 8 } & \multicolumn{2}{c}{$\begin{array}{c}\text { Intuitive } \\
(n=143)\end{array}$} & \multicolumn{2}{c}{$\begin{array}{c}\text { Empiricist } \\
(n=320)\end{array}$} & \multicolumn{2}{c}{$\begin{array}{c}\text { Rationalist } \\
(n=94)\end{array}$} & $\begin{array}{c}\text { Total } \\
(n=557)\end{array}$ \\
\cline { 2 - 8 } Personal Style & $M$ & $S E$ & $M$ & $S E$ & $M$ & $S E$ & $M(S D)$ \\
\hline Attention & 2,89 & 0,08 & $3,14_{\mathrm{b}}$ & 0,05 & $3,34_{\mathrm{c}}$ & 0,09 & $3,12(1,16)$ \\
Expression & $4,03_{\mathrm{a}}$ & 0,08 & $3,75_{\mathrm{b}}$ & 0,05 & $3,57_{\mathrm{b}}$ & 0,09 & $3,79(0,96)$ \\
Operation & $2,16_{\mathrm{a}}$ & 0,07 & $2,299_{\mathrm{a}}$ & 0,09 & $2,40_{\mathrm{a}}$ & 0,05 & $2,27(0,94)$ \\
Involvement & $3,35_{\mathrm{a}}$ & 0,08 & $3,29_{\mathrm{a}}$ & 0,05 & $3,36_{\mathrm{a}}$ & 0,09 & $3,32(0,91)$ \\
\hline
\end{tabular}

Note. Adjusted mean scores with different subscripts on the same line are significantly different from one another. For personal style dimensions, high scores on each dimension represent: attention (more narrowly focused), expression (greater closeness), operation (more structured) and involvement (greater degree). The response scale for each dimension ranged from 1 to 6 . The covariates age, years of experience, and theoretical orientation were controlled for.

In terms of emotion regulation modes, univariate tests revealed significant between-groups differences only in upregulation, $F(2,554)=4.09, p<0.001$. Post hoc
(Bonferroni) analysis revealed that intuitives $(M=4.97$, $S E=0.07)$ scored higher than rationalists $(M=4.66, S E=$ 0.08 ) on that dimension.

\section{DISCUSSION}

The main objective of this study was to examine the relations among therapists' epistemic orientation, personal style, and emotion regulation. In general, findings point out to recent debates concerning how personal epistemology might contribute to research on therapists' personal characteristics (e.g., Brucato \& Neymeier, 2009; Lee et al., 2013; Toska et al., 2010).

\section{Epistemic Orientation and Therapist's Personal Style}

Results suggest that predominantly intuitive therapists behave differently from those who are predominantly empiricist or rationalist in terms of attention and expression. More specifically, intuitives were more likely to report listening to patients in an open and receptive manner and attending to different aspects that occur during sessions. Furthermore, they emphasized emotional processing and expression by using emotions evoked in the therapeutic process as sources of information capable of guiding clinical interventions. Intuitives also tended to more strongly agree that emotions are instruments of therapeutic chance.

These findings seem to support theoretical issues raised by authors who hold that intuition might be a powerful source of information and an effective instrument of change in clinical practice. According to Welling (2005), therapists' intuitive resources seem to be closely associated with affective and relational elements of the therapeutic process. $\mathrm{He}$ also underlines that receptive attention might facilitate the identification of intuitive phenomena in clinical practice. Similarly, Bohart (1999) and Bove and Rizzi (2009) argue that intuitive phenomena might be more easily captured and used through openness to experience. It may be that a receptive stance, widely advocated by these authors, expresses itself in therapists' broadly focused attention and use of emotions in the clinical setting. Recent studies on dual styles of information processing (i.e., intuitive and analytical) also seem to support this claim. In these studies, an intuitive style has been described as automatic, preconscious, holistic, associationistic, non-verbal, and highly affective (Epstein \& Epstein, 2016), and it has been often associated with openness to experience, mindfulness (i.e., a type of nonjudgmental attention directed to experiences in the present moment), emotional expressivity, and spontaneity (e.g., Epstein \& Epstein, 2016; Sinclair, 2011).

Predominantly rationalist therapists, in turn, were more likely to report narrowly focusing their attention. Furthermore, in comparison to intuitives, they were less likely to emphasize the role played by emotions in their clinical practice. Lee et al. (2013) found a similar result when comparing therapists who leaned towards a rationalist epistemology with those who leaned towards constructivism. In their study, rationalist therapists tended to keep their attention more narrowly focused and were less likely to emphasize emotional processing in their clinical practice. Such findings also seem to be supported by the dual processing style literature, according to which, individuals with strong rationalist leanings are characterized as having tight emotional control, strategic thinking, and intentional actions (e.g., Epstein \& Epstein, 2016; Rancourt, 1990).

Predominantly empiricist therapists displayed intermediate scores situated between those of intuitives and rationalists in all personal style dimensions. However, these 
differences were statistically significant only in attention, when compared to the two other groups. It should be noted that attention refers to those processes involved in how therapists select and organize patients' information.

In this regard, it is worth underscoring a theoretical issue raised by Clark (1973) who, in a simple and provocative essay, underscored the need to value an empiricist stance, primarily via observation, during psychotherapy training. This author viewed empiricism as a way of moderating the influence of concepts (e.g., diagnostic labelling) and subjective experiences on therapeutic work. Clark also claimed that observation could help support the use of intuitionism and rationalism without circumscribing therapists' experience to any of them. As such, this orientation to knowledge would function as an equilibrium point. This might help explain, in part, why predominantly empiricist therapists' average scores situated between those of the rationalists and the intuitives on the attention dimension. Whereas predominantly intuitive and rationalist therapists tended to move towards the extremities of this dimension (broadly focused - narrowly focused), empiricists adopted an intermediate stance. Rancourt (1990) seems to have pointed in that direction when he delineated the behavioral profile of individuals who are strongly leaned towards empiricism. Such individuals seem to be inclined to consensus and harmony. However, he did not offer empirical evidences of such descriptors.

In this context, the scarcity of studies regarding this epistemic orientation does not allow further comparisons and interpretations. Indeed, studies on personal epistemology in psychotherapy research, though rare, have been concerned mainly with the polarization between constructivism and rationalism, or between the theoretical approaches that seem to strongly endorse these epistemic orientations (e.g., Lee et al., 2013; Toska et al., 2010). This is not surprising since, in the present study, rationalist and intuitive modes were the ones which showed the greater number of moderate associations with personal style dimensions and emotion regulation strategies.

Still concerning the relations between epistemic orientation and therapist's personal style, no intergroup differences were found in the operation dimension. This seems to contradict previous findings regarding the selection and implementation of clinical interventions by therapists (e.g., Lee et al., 2013). It is noteworthy that, in the present study, therapists' theoretical orientation was controlled. According to previous studies, therapists of different theoretical approaches seem to vary considerably in terms of their operative style (e.g., Castañeiras et al., 2008; Palma \& Gondim, 2016). Therefore, it can be assumed that therapists' operative style might be more sensitive to the prescriptions of their theoretical approaches than to their epistemic orientation.

\section{Emotion Regulation:Associations with Epistemic Orientation and Personal Style}

Regarding emotion regulation modes, a stronger association was observed between upregulation and intuitionism. Individuals with a strong leaning towards intuition have been theoretically and empirically described as more present centered and emotionally expressive (e.g., Epstein, 2010; Rancourt, 1990; Stickle \& Arnd-Caddigan, 2019). In the present study, compared to rationalists, intuitives were more likely to report drawing on resources to intensify their positive emotions by using upregulation strategies, such as savoring the present moment and capitalization (i.e., sharing positive emotions with others). One possible explanation is that intuitive therapists, by relying on their affective states to guide their actions and decisions, are capable of making the most of their positive emotions when in contact with situations that evoke such affects. Furthermore, the association between upregulation and expression makes sense in that both dimensions emphasize the expression, sharing and processing of emotions, but for different reasons. Whereas upregulation aims at extending the effects of positive emotions through their expression and sharing, expression aims at promoting therapeutic change by using these strategies.

As for downregulation (i.e., the buffering of harmful effects of negative emotions), no statistically significant between-groups differences were found as a function of predominant epistemic orientation. However, weak correlations were found between this emotion regulation mode and empiricist and rationalist modes. Downregulation strategies, such as cognitive reappraisal, might demand resources from both epistemic modes at different levels. These strategies generally involve cognitive elements, thus requiring the use of assessment, planning, and monitoring. These actions seem to be closely associated with both empiricist and rationalist modes to different degrees. Additionally, it is worthy to mention that empiricism's positive association with both up- and downregulation strategies might demonstrate its capacity to manage elements of both regulatory modes.

In terms of therapist's personal style, downregulation was negatively associated with expression and involvement. As for the first association, it should be emphasized that downregulation consists primarily of cognitive elements and deemphasizes emotional expression. Therefore, such negative association between downregulation and expression is not surprising. However, the negative relationship between downregulation and involvement points out to interesting issues associated with the therapist self-care literature. Studies have shown that high levels of therapist involvement are associated with some harmful effects of professional practice, such as burnout syndrome and compassion fatigue (e.g., Rupert, Miller, \& Dorociak, 2015; Thomson, 
Amatea, \& Thomson, 2014). This type of involvement has been termed stressful involvement as opposed to other healthier, more beneficial types, such as healing involvement (Rønnestad \& Skovholt, 2013). In the present study, high levels of downregulation were associated with lower levels of involvement, which might suggest that downregulation strategies may play a protective role against the potentially detrimental effects of this stylistic pattern of the therapist. This result was consistent even after controlling for age and years of experience.

\section{Implications for Training, Practice, and Therapist's Personal Well-Being}

As more systematic research on the person of the therapist is conducted in the context of treatment efficacy and effectiveness (e.g., Baldwin \& Imel, 2013; Fife et al., 2014; Heinonen et al., 2014), the need for studies on therapist's behavioral dimensions and their predictors become more apparent. Such studies might generate invaluable contributions and guidelines for professional training and personal development. Given some robust findings on the impact of therapist's personal attributes on treatment outcomes, self-knowledge should be more emphasized during training (e.g., Fife et. al., 2014; Heinonen et al., 2014; Rønnestad \& Skovholt, 2013).

As Levitt and Piazza-Bonin (2015) point out, training programs should explicitly encourage self-reflection and emotional and interpersonal awareness in therapists. In this sense, literature seems to concur that therapists with greater knowledge of the antecedents and consequences of their behaviors are more adept at managing and maximizing treatment outcomes. Studies have shown that therapist's personal characteristics might have an impact on alliance formation (Heinonen et al., 2014) and on treatment outcomes (Heinonen, Lindfors, Laaksonen, \& Knekt, 2012) depending on treatment length. For instance, an active and extroverted style was associated with better results in a brief treatment whereas a more cautious and non-intrusive style was more conducive to positive changes in a long-term treatment (Heinonen et al., 2012). Taken together, results suggest that, to some extent, therapists need to develop a wide and varied repertoire, one that is sensitive to the different contextual demands of clinical practice (e.g., treatment length, type of psychological disorder, and client's personal characteristics).

Dryden and Spurling (1989) argue that therapist's style must be flexible to allow its optimal functioning, thus impacting service quality in a positive manner. Although emotional facilitation and the creation of an affective climate conducive to therapeutic practice are highly desirable, excessive focus on these aspects might lead to emotional exhaustion in the clinician. Likewise, excessive emphasis on structuring the therapeutic process might negatively impact alliance formation, thus compromising treatment outcomes (e.g., Dryden \& Spurling, 1989; Norcross, 2011). In this context, knowing one's epistemic orientation and associated personal styles could help in the construction of more flexible repertoires. Thus, such knowledge should be explicitly encouraged in training processes, as has been suggested by Dryden and Spurling (1989) and empirically supported by Heinonen et al.`s studies (2012; 2014).

Studies concerning the person of the therapist should also consider variables associated with his or her wellbeing, which is also positive predictor of variables related to treatment (e.g., Baldwin \& Imel, 2013; Nissen-Lie et al., 2015). In the present study, the association between different epistemic orientations and emotion regulation strategies shows how therapist's preferred ways of knowing might go beyond the clinical context and be useful in the development and employment of self-care strategies. Whereas the rationalist mode seems to favor the use of downregulation strategies, the intuitive mode is clearly associated with upregulation strategies. The empiricist mode, in turn, was associated with both emotion regulation modes, which might indicate its capacity to articulate elements pertaining to the two regulatory processes, such as a time orientation to the present moment as in upregulation (e.g., savoring the present moment) and the coordination of elements that allow for new interpretations of negative emotion eliciting events as in downregulation (e.g., reappraisal of the situation).

Finally, downregulation strategies appear to play a protective role, lowering therapist's level of negative or stressful involvement with issues concerning his or her practice. All these aspects have implications for therapist's career at all levels, from training to effective professional practice, and can therefore be included in curricula.

\section{Limitations and Future Research}

This study has some limitations that need to be considered. This is a correlational and cross-sectional study, which precludes conclusions about the direction of causality between the investigated variables. Moreover, although the sample was large and quite diverse in terms of theoretical orientation and geographic distribution in the national territory, the method of data collection via the Internet, the voluntary nature of participation, and the use of self-report instruments limit the generalization of the data. Self-report instruments, for example, are subject to distortion and social desirability effects and may not adequately reflect participants' actual behavior (Picardi $\&$ Masick, 2014). As already mentioned, the sample of this study consisted of participants from all regions of Brazil, and their sociodemographic and professional characteristics were similar to those present in samples from other international studies with psychotherapists (e.g., predominance of women and psychologists, middle aged group, and the most endorsed theoretical approaches being 
psychoanalysis, cognitive therapy, and behavior analysis). This large number of participants may have contributed to better representativeness of the sample.

It is also worth mentioning that, given the heterogeneity of the sample, some confounding variables could not be completely eliminated, which would allow more accurate conclusions about the relationships among the variables. Of course, it is possible to assume that covariates other than those controlled for in this study (i.e., age, years of experience, and theoretical orientation) also influence the relationships found.

Future studies could test the predictive role of epistemic orientation and personal style, as conceptualized here, in the results of different treatment modalities (e.g., brief and long term). In addition, the empiricist orientation, the one endorsed by most therapists in this study as their predominant mode, needs to be thoroughly investigated for a better understanding of its particularities. The scarcity of studies addressing this epistemic orientation did not allow more robust comparisons and interpretations of the relationships found. As mentioned, studies of therapist's personal epistemology tend to polarize between rationalists and constructivists. To conclude, future studies that encompass therapist's emotional regulation strategies could also emphasize upregulation strategies by investigating their possible impact on treatment-associated variables (e.g., therapeutic alliance).

\section{CONCLUSIONS}

This study contributed to the identification of predictors and correlates of therapist's stylistic patterns and emotional regulation, demonstrating that epistemic orientation can be an important source of individual variation among these professionals. In doing so, it follows the recent trend in studies on the influence of epistemic orientation on psychotherapy, more specifically on the person of the therapist. To our knowledge, this is the first study of its kind conducted in Brazil, which allows comparisons and dialogues with international studies. In addition, it expanded the scope of research into therapist characteristics by including therapist's intuitive and empiricist orientations and upregulation strategies. Previous studies in this area were mainly devoted to the study of constructionist/constructivist and rationalist orientations and their associations with some aspects of clinical practice, such as the use of techniques, the choice of theoretical model, and the therapeutic alliance. The present study, in turn, sought to emphasize the person of the therapist, addressing aspects related to their behavioral and affective dimensions. In this sense, it is in line with Downing's (2000) proposal concerning the need to investigate "lived modes of knowing". The conclusions also contribute to the growing literature on the formation and development of the person of the therapist, bringing other elements that may support recent training models that advocate for the awareness of intra- and interpersonal aspects as prerequisites for effective therapeutic action (e.g., Aponte \& Kissil, 2016; Baldwin, 2013).

\section{REFERENCES}

Aponte, H. J., \& Kissil, K. (2016). The person of the therapist training model: Mastering the use of self. New York, NY: Routledge.

Arthur, A. R. (2000). The personality and cognitive-epistemological traits of cognitive behavioral and psychoanalytic psychotherapists. British Journal of Medical Psychology, 73, 243-257. doi: 10.1348/000711200160453

Baldwin, M. (2013). The use of self in therapy. New York, NY: Routledge.

Baldwin, S. A., \& Imel, Z. E. (2013). Therapist variables in psychotherapy research. In M. J. Lambert (Ed.), Bergin and Garfield's Handbook of Psychotherapy and Behavior Change (6th ed., pp. 258-297). New York: Wiley.

Bohart, A. C. (1999). Intuition and creativity in psychotherapy. Journal of Constructivist Psychology, 12, 287-311. doi: 10.1080/107205399266028

Bove, S., \& Rizzi, M. (2009). Listening to intuition: Reflections on unconscious processes in the therapeutic relationship. Transactional Analysis Journal, 39(1), 39-45. doi: 10.1177/036215370903900105
Brucato, B., \& Neimeyer, G. (2009). Epistemology as a predictor of psychotherapists' self-care and coping. Journal of Constructivist Psychology, 22(4), 269-282. doi: 10.1080/10720530903113805

Carvalho, H., Corbella, S., \& Matos, P.M. (2011). Confirmatory factor analysis of the Portuguese brief version of the Personal Style of the Therapist Questionnaire (PST-Q). Revista Argentina de Clínica Psicológica, 20(1), 79-90. Recuperado de http://www.clinicapsicologica.org.ar/download_file. php?idt=72\&hax $=2$ THZS41YO

Castañeiras, C., Ledesma, R., García, F., \& Fernández-Álvarez, H. (2008). Evaluación del estilo personal del terapeuta: Presentación de una versión abreviada del EPT-C. Terapia Psicológica, 26(1), 5-13. doi:10.4067/S0718-48082008000100001

Downing, J. N. (2000). Between conviction and uncertainty: Philosophical guidelines for the practicing psychotherapist. New York, NY: SUNY Press

Epstein, S. (2010). Desmystifying intuition: What it is, what it does, and how it does it. Psychological Inquiry, 21(4), 295-312. doi: 10.1080/1047840X.2010.523875

Fernández-Álvarez, H., García, F., Lo Bianco, J., \& Santoña, S. (2003). Assessment Questionnaire on the personal style of 
the therapist PST-Q. Clinical Psychology and Psychotherapy, 10(2), 116-125. doi: $10.1002 / \mathrm{cpp} .358$

Fife, S. T., Whiting, J. B., Bradford, K., \& Davis, S. (2014). The therapeutic pyramid: A common factors synthesis of techniques, alliance, and way of being. Journal of Marital and Family Therapy, 40 (1), 20-33. doi: 10.1111jmft.12041

Gondim, S. M. G., Pereira, C. R., Hirschle, A. L. T., Palma, E. M. S., Alberton, G. D., Paranhos, J., ... Ribeiro, W. R. B. (2015). Evidências de validação de uma medida de características pessoais de regulação das emoções. Psicologia: Reflexão e Crítica, 28(4), 659-667. doi: 10.1590/1678-7153.201528403

Gross, J. J. (2015). Emotion regulation: Current status and future prospects. Psychological Inquiry, 26, 1-26. doi: 10.1080/1047840X.2014.940781

Heinonen, E., Lindfors, O., Laaksonen, M. A., \& Knekt, P. (2012). Therapists' professional and personal characteristics as predictors of outcome in short- and long-term psychotherapy. Journal of Affective Disorders, 138(3), 301-312. doi: 10.1016/j. jad.2012.01.023

Heinonen, E., Lindfors, O., Harkanen, T., Virtala, E., Jaaskelainen, T., \& Knekt, P. (2014). Therapists' professional and personal characteristics as predictors of working alliance in short-term and long-term psychotherapies. Clinical Psychology and Psychotherapy, 21(6), 475-495. doi: 10.1002/cpp.1852

Hofman, S. G. (2016). Emotion in therapy: From science to practice. New York, NY: Guilford Press.

Jeffrey, A. (2012). The Clinical Intuition Exploration Guide: A decision-making tool for counselors and supervisors. The Family Journal: Counselling and Therapy for Couples and Families, 20(1), 37-44. doi: 10.1177/1066480711425469

Knight, C. (2012). Therapeutic use of self: Theoretical and evidencebased considerations for clinical practice and supervision. The Clinical Supervisor, 31(1), 1-24. doi.:10.1080/0732522 3.2012 .676370

Lee, J. A., Neimeyer, J. G., \& Rice, K. G. (2013). The relationship between therapist epistemology, therapy style, working alliance, and interventions use. American Journal of Psychotherapy, 67(4), 323-345.

Millgram, Y., Joorman, J., Huppert, J. D., \& Tamir, M. (2015). Sad as a matter of choice? Emotion regulation goals in depression. Psychological Science, 26(8), 1216-1228. doi: 10.1177/0956797615583295

Nelis, D., Quoidbach, J., Hansenne, M., \& Mikolajczak, M. (2011). Measuring individual differences in emotion regulation: The Emotion Regulation Profile - Revised (ERP-R). Psychologica Belgica, 51, 49-91. doi:10.5334/pb-51-1-49
Orlinsky, D. E., \& Rønnestad, M. H. (2005). How psychotherapists develop: A study of therapeutic work and professional growth. Washington, D.C. American Psychological Association.

Palma, E. M. S., \& Gondim, S. M. G. (2016). Questionário Reduzido do Estilo Pessoal do Terapeuta: Evidências de validade. Avaliação Psicológica, 15(3), 298-307. https://dx.doi. org/10.15689/ap.2016.1503.02

Palma, E. M. S., Gondim, S. M. G., \& Aguiar, C.V.N. (2018). Epistemic Orientation Short Scale: Development and validity evidence in a sample of psychotherapists. Paidéia, 28, e2817. doi: 10.1590/1982-4327e2817

Picardi, C. A., \& Masick, K. D. (2014). Research methods: Designing and conducting research with real-world focus. Thousand Oaks, CA: Sage Publications.

Pieterse, A. L., Lee, M., Collins, N. M., \& Ritmeester, A. (2013). Towards an integrated model of self-awareness development for counseling and psychotherapy training. Counseling Psychology Quarterly, 26, 190-207.doi:10.1080/09515070. 2013.793451

Rancourt, R., (1990). Le guide du consultant pour l'interprétation des styles épistémiques. Gloucester, Ontario. Les éditions Impact.

Rønnestad, M. H., \& Skovholt, T. M. (2013) The developing practitioner: Growth and stagnation of therapists and counselors. New York, NY: Routledge.

Royce, J. R., \& Mos, L. P. (1980). Manual: Psycho-Epistemological Profile. The University of Alberta.

Sinclair, M. (2011). Handbook of intuition research. Massachusetts, USA: Edward Elgar Publishing.

Stickle, M., \& Arnd-Caddigan, M. (2019). Intuition in psychotherapy: From research to practice. New York, USA. Routledge.

Tamir, M. (2015). Why do people regulate their emotions: A taxonomy of motives in emotion regulation. Personality and Social Psychology Review, 1-24. doi: 10.1177/1088868315586325

Toska, G. A., Neimeyer, G. J, Taylor, J. M., Kavas, A. B., \& Rice, K. G. (2010). Epistemology and allegiance: Exploring the role of therapists' epistemic commitments on psychotherapy outcomes. European Journal of Psychotherapy and Counselling, 12(1), 65-77. doi: 10.1080/13642531003637783

Vandenberghe, L., \& Silvestre, R. L. S. (2014). Therapists' positive emotions in-session: Why they happen and what they are good for. Counselling and Psychotherapy Research: Linking research with practice, 14(2), 119-127. doi: 10.1080/14733145.2013.790455

Welling, H. (2005). The intuitive process: The case of psychotherapy. Journal of Psychotherapy Integration, 15(1), 19-47. doi: 10.1037/1053-0479.15.1.19 